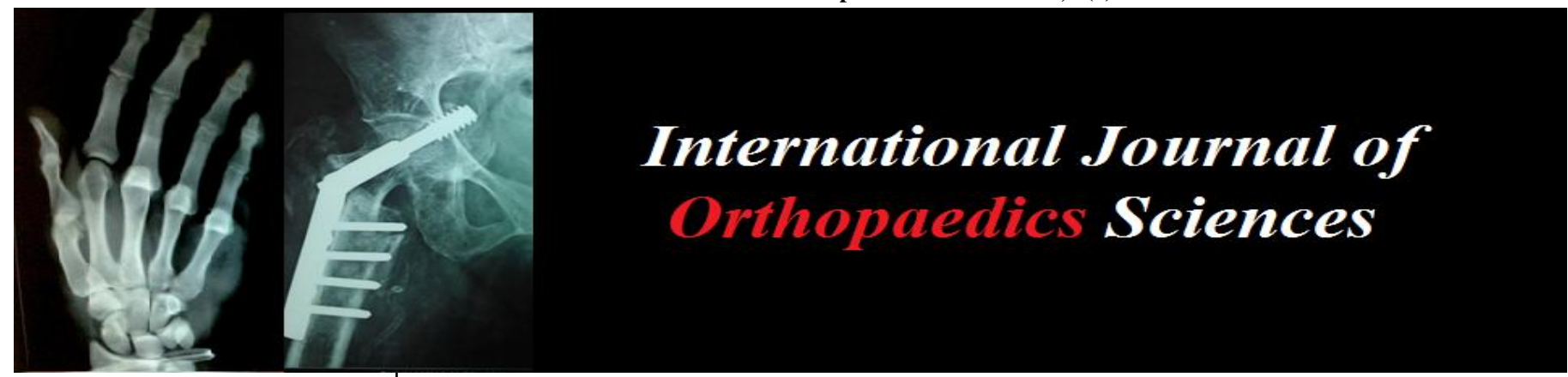

ISSN: $2395-1958$

IJOS 2018; 4(1): 873-877

(C) 2018 IJOS

www.orthopaper.com

Received: 16-11-2017

Accepted: 17-12-2017

Dr. S Prabhakar

D Ortho. M. S. Ortho. D. N. B

Ortho. Senior Assistant

Professor, Department Of

Orthopedics, Government

Kilpauk Medical College

Hospital Chennai, India

Dr. R Manoj Kumar

M. S. Ortho, Assistant Professor,

Department Of Orthopaedics,

Government Kilpauk Medical

College hospital Chennai, India

Dr. Kathir Azhagan

S Resident Department of

Orthopaedics, Government

Stanley Medical College Chennai,

India
Correspondence

Dr. R Manoj Kumar

M. S. Ortho, Assistant Professor,

Department Of Orthopaedics,

Government Kilpauk Medical

College hospital Chennai, India

\section{A study on clinical, functional and radiological outcome of high velocity tibial plateau fractures managed by dual plating}

\author{
Dr. S Prabhakar, Dr. R Manoj Kumar, Dr. Kathir Azhagan
}

DOI: $\underline{\text { https://doi.org/10.22271/ortho.2018.v4.i1m.126 }}$

\section{Abstract}

Tibial plateau fractures are intra-articular fractures of major weight bearing joint ${ }^{[1]}$. These fractures represent a wide spectrum of severity which ranges from simple injuries with predictably excellent outcome after nonperative treatment to complex fracture patterns that challenge even most experienced surgeons ${ }^{[2]}$. Among wide spectrum of operative management Dual plating via two incision is preferred technique as it has its own advantages when compared to other modalities of treatment such as Lateral locking plate, Hybrid external fixator, Ilizarov, LISS, External fixator with limited internal fixation. Hence this study is done to emphasise the importance of double plating in management of Scahtzker type V \& VI fractures based on Honkonen Jarvinen criteria (1992) and reported the results.

Keywords: Tibial plateau fractures, dual plating

\section{Introduction}

The management of tibial plateau fractures has improved dramatically for the past 50 years. In the early 1950's these fractures were treated none operatively and many surgeons published favourable results by this management ${ }^{[2]}$.

Operative treatment includes:

1. Isolated lateral locking plate

2. Dual plating with lateral locking plate and posteromedial buttress plate

3. Hybrid external fixator

4. Ilizarov

5. LISS

Each technique has its own merits and demerits.Dual Plating is preferred over other techniques as it has several advantages:

- Better visualisation of fracture fragments, especially posteromedial fragment and articular surface ${ }^{[9]}$

- Dual incision reduces wound complications ${ }^{[9]}$.

- Both lateral and medial column is fixed to obtain stability ${ }^{[6]}$.

- Achieves interfragmentary compression ${ }^{[7]}$.

- $\quad$ Rigid construct ${ }^{[7]}$.

Hence we preferred the dual plating as our fixation of choice and reported the functional and radiological outcome

\section{Aim of the Study}

The aim of the study is to prospectively analyse the clinical, functional \& radiological outcome of high velocity tibial plateau fractures managed by dual plating at Govt. Kilpauk Medical College Hospital between August 2013 and August 2015.

\section{Materials and Methods}

Our study is a prospective study conducted at Department of Orthopaedics, Govt. Kilpauk Medical College Hospital between August 2013 and August 2015.

$$
\sim 873 \sim
$$


Inclusion Criteria

Patients with High velocity tibial plateau fractures who are,

1. Skeletally mature \& age between 20-60 years.

2. Included in the criteria of depression / displacement of articular surface of $>2 \mathrm{~mm}$

3. Included in Schatzker's Classification of tibial plateau fractures Type V \& VI.

\section{Exclusion Criteria}

Patients with

1. Open fractures

2. Pathological fractures

3. Associated pre-existing joint disease (osteoarthritis )

4. Associated Neurovascular injury / head injury

5. Skeletally immature patients.

6. Twenty one patients were included in the study who satisfied these criteria.

Age Distribution

\begin{tabular}{|c|c|c|}
\hline Age & Number & Percentage \\
\hline $30-40$ & 7 & 33.3 \\
\hline $40-50$ & 11 & 52.4 \\
\hline $50-60$ & 3 & 14.3 \\
\hline
\end{tabular}

\section{Sex Distribution:}

Male: 16

Female: 5

Mode of Injury All 21 sustained Road traffic accident. Side of Injury

\begin{tabular}{|c|c|c|}
\hline Side & Number & Percentage \\
\hline Right & 9 & 42.9 \\
\hline Left & 12 & 57.1 \\
\hline
\end{tabular}

Fracture Types

\begin{tabular}{|c|c|c|}
\hline Fracture type & Number & Percentage \\
\hline Type V & 7 & 33.3 \\
\hline Type VI & 14 & 66.7 \\
\hline
\end{tabular}

\section{Time of surgery}

The average period from day of injury to surgery was 5.3 days with a range between 3 to 9 days.

\section{Post-Operative Follow UP}

Patient was reviewed in Out Patient Department every 4 weeks and $\mathrm{X}$ rays were taken every month for first 6 months to assess union. Partial weight bearing was started after 8 weeks. Full weight bearing was allowed after radiological evidence of bony union was achieved. After 6 months patients were reviewed every 3 months.

\section{Assessment}

The Clinical, Functional and Radiological assessment was done based on Honkonen Jarvinen Criteria (1992).

Our patients had average follow up for 15.7 months ranging from 9 to 22 months.

\section{Result}

- The incidence of male was more compared to females in the

- Ratio-3.2:1.

- The nature of injury is high velocity injury as it is explained by all patient sustaining road traffic accident. None had sustained injury as a result of trivial trauma as occurs in elderly with osteoporotic bone.

- The incidence of fracture in right side was $42.9 \%$ and in left side was $57.1 \%$ which nearly equal.

- Among 21 cases, the incidence of fracture in age group 40-50 was $52.4 \%$

- Of 21 fractures, 7 patients (33.3\%) had Type V fracture and 14 patients $(66.7 \%)$ had Type VI fracture.

- There were no associated injury in all patients

- All patients underwent standard surgical procedure by anterolateral \& posteromedial approach.

- Lateral locking plates were used for lateral plateau and T/L Buttress, Semi tubular, Recon plates were used for medial plateau.

- Bone Grafting was used for 9 patients $(42.9 \%)$ to fill metaphyseal defect.

- Time required for union ranged from 11 to 16 weeks with average being 12.9 weeks

\section{Result Analysis}

Honkonen Jarvinen Criteria was used for evaluating Clinical, Functional and Radiographic results.

\section{HJ Clinical Outcome}

\begin{tabular}{|c|c|c|c|c|}
\hline Criteria & Excellent & Good & fair & poor \\
\hline Extension lag & $21(100 \%)$ & - & - & - \\
\hline Knee flexion & $11(52.3 \%)$ & $8(38.1 \%)$ & $2(9.5 \%)$ & - \\
\hline Thigh atrophy & $19(90.5 \%)$ & $2(9.5 \%)$ & - & - \\
\hline Instability & $17(81 \%)$ & $4(19 \%)$ & - & - \\
\hline Mean \% & $81 \%$ & $16.6 \%$ & $2.4 \%$ & \\
\hline
\end{tabular}

- None of the patients had extension lag.

- $\quad$ The average knee flexion was $125.9^{\circ}$ with range from $95^{\circ}$ to $135^{\circ}$. The reason for fair range of motion in two patients was poor adherence to physiotherapy.

- The average thigh atrophy was $0.09 \mathrm{~cm}$ with range from $0-1 \mathrm{~cm}$

- There was grade 1 anteroposterior instability in 4 patients.

\section{HJ Functional Outcome}

\begin{tabular}{|c|c|c|c|c|}
\hline Criteria & Excellent & good & fair & Poor \\
\hline Walking & $21(100 \%)$ & - & - & - \\
\hline Stair climbing & $20(95 \%)$ & $1(4.8 \%)$ & - & - \\
\hline Squatting & $13(61.9 \%)$ & $8(38.1 \%)$ & - & - \\
\hline Jumping & $11(52.4 \%)$ & $6(28.6 \%)$ & $3(14.3 \%)$ & $1(4.8 \%)$ \\
\hline Duck walking & $11(52.4 \%)$ & $5(23.8 \%)$ & $4(19 \%)$ & $1(4.8 \%)$ \\
\hline Mean \% & $72.3 \%$ & $19.1 \%$ & $6.7 \%$ & $1.9 \%$ \\
\hline
\end{tabular}

- All 21 patients were able to walk excellent.

- 20 patients had excellent stair climbing function but it was impaired in 1 patient due to pain.

- 13 patient were able to squat well while it was impaired in 8 patients due to pain.

- 11 patients were able to jump normally and it was impaired due to pain in 6 patients. 3 patients were able to jump only with the aid of uninjured leg. 1 patient was not able to jump.

- 11 patients were able to duck walk normally and 5 patients were able to keep only a few steps. 4 patients were able to keep only one step. 1 patient was unable to do. 
HJ Radiological outcome

\begin{tabular}{|c|c|c|c|c|}
\hline Criteria & excellent & good & fair & Poor \\
\hline Plateau tilt & $19(90.5 \%)$ & $2(9.5 \%)$ & - & - \\
\hline Varus / valgus tilt & $21(100 \%)$ & - & - & - \\
\hline Articular step off & $18(85.7 \%)$ & $3(14.3 \%)$ & - & - \\
\hline Condylar widening & $17(81 \%)$ & $4(19 \%)$ & - & - \\
\hline Joint space narrowing & $16(76.2 \%)$ & $4(19 \%)$ & $1(4.8 \%)$ & - \\
\hline Mean \% & $87 \%$ & $12 \%$ & $1 \%$ & - \\
\hline
\end{tabular}

- 19 patients scored excellent and 2 patients had scored well with $<5^{\circ}$ plateau tilt compared to opposite side.

- All 21 patients had excellent results with no varus / valgus tilt.

- 18 patients did not have any particular step off. 3 patients had 1-3 mm articular step.

- 17 patients had no condylar widening. 4 patients had condylar widening of $1-5 \mathrm{~mm}$.

- 16 patients did not have any joint space narrowing, 4 patients had $<50 \%$ joint space narrowing 1 patient had $>$ $50 \%$ joint space narrowing.

\section{Complications}

- 3 patients had superficial infection which improved with wound debridement, sterile dressing and intravenous antibiotics.

- 2 patients had knee flexion of $<100^{\circ}$ which was due to poor physiotherapy.

- 1 patient had implant prominence of $4 \mathrm{~mm}$ cancellous screw which was removed and revised with another screw.

- 4 patients had occasional pain which was managed with analgesics

\section{Discussion}

Complex tibial plateau fractures still remain a challenge to most Orthopaedic surgeons. Road traffic accident being the commonest mode of injury leading to these high velocity fractures. To reconstruct a stable painless mobile knee is a tough task and requires expertise and sufficient technical knowledge. Historically due to poor technique of fixation with dual plates with single midline incision or Mercedes Benz incision, alternate methods of fixation with Ilizarov ring fixation hybrid external fixation were being employed. Single incision technique had high incidence of wound breakdown and infection ${ }^{[6]}$.

With the advent of isolated lateral plating with locking compression plate the spectrum has shifted towards locking plate with medial fragment being stabilised by screws passed through lateral plate. Varus collapse in these patients raised the question of its sustainability and the reason found to be inadequate fixation of posteromedial fragment. This has paved way for dual plating via two incision technique. A double incision Double plating technique is recommended by the Association for Osteosynthesis / Association for the Study of Internal Fixation for the treatment of complex tibial plateau fractures ${ }^{[9]}$.

Locking plates provide fixed angle stability and we hypothesised that using lateral locking plates instead of buttress plate may help to prevent Secondary loss of reduction and alignment. If secondary loss of reduction occurs, osteoarthritis will occur even if primary was satisfactory ${ }^{[8]}$.

In our study, males outnumbered females in the ratio 3.2:1. This is explained by more active life style of males and higher chance of road traffic accidents. This is in accordance with the series of 14 patients reported by Eggli et al. in which 10 were male and 4 were female ${ }^{[11]}$. All 21 patients sustained road traffic accident. Distribution of incidence between sides were near equal. We had 7 schatzker Type V \& 14 schatzker Type VI with preponderance of the latter.

Our study reported Honkonen Jarvinen Clinical outcome to be $81 \%$ excellent, $16.6 \%$ good and $2.4 \%$ fair. The functional outcome was $71.3 \%$ excellent, $19.1 \%$ good, $6.7 \%$ fair and $1.9 \%$ poor. The Radiological outcome showed $87 \%$ excellent, $12 \%$ good, $1 \%$ fair results.

As this is a short term study, the results may also vary with further follow up.

Bone grafts were used in $9(42.9 \%)$ of 21 patients after elevation of depressed articular surface. The mean time of union was 12.9 weeks ranging from 11 to 16 weeks. Bone grafting did not contribute to faster healing as metaphyseal defects heal well without bone grafts. In the report published by Eggli et al bone grafting was employed in 11 of 14 patients [11].

Knee flexion of $95^{\circ}$ and $100^{\circ}$ was noted in two patients and physiotherapy was encouraged. Superficial infection occurred in 3 patients and healed with debridement, wound dressing and intravenous antibiotics. Occasional pain in 4 patients was managed with analgesics. There were no associated injuries in our patients

\section{Conclusion}

- From our study we conclude that,

- High velocity tibial plateau fracture have excellent to good clinical, functional and radiological outcome.

- Early mobilisation of the joint provides good range of motion.

- Posteromedial plating provides a buttress to posteromedial fragment and thereby prevents varus collapse.

- The patients with good soft tissue cover should undergo anatomical reduction and rigid fixation immediately without deferring time.

- This is a short term study and need follow up to predict the further outcome.

\section{Case 1 lustration}

60 year old Male who sustained Road traffic accident to his right leg had Type V Schatzker tibial plateau fracture and was operated after 8 days with ORIF using dual plating. His Post Op Period was uneventful and started Knee Mobilization: $3^{\text {rd }}$ day, partial weight bearing: $12^{\text {th }}$ week, Full weight bearing: $16^{\text {th }}$ week. During his Follow up at 18 months, His HJ clinical, functional and radiological outcome were good

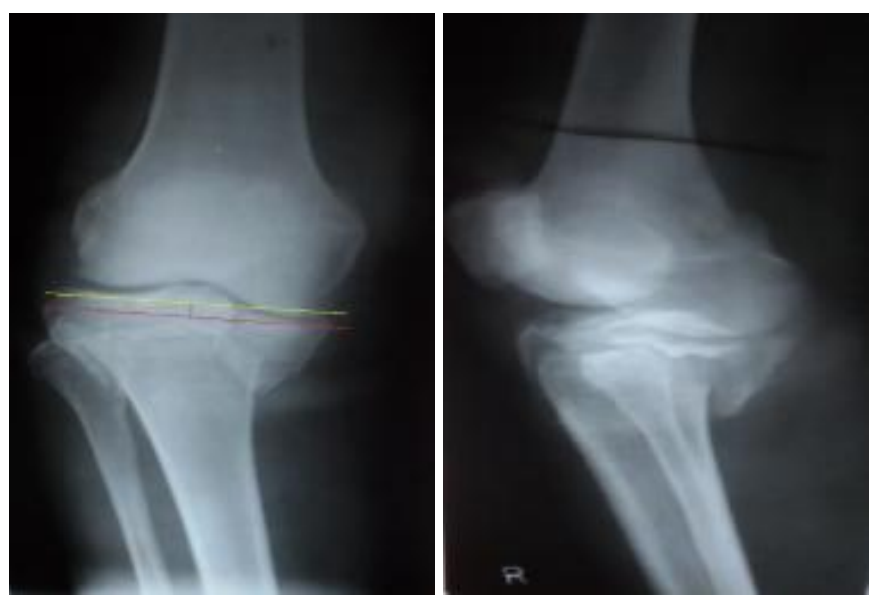

Pre op 

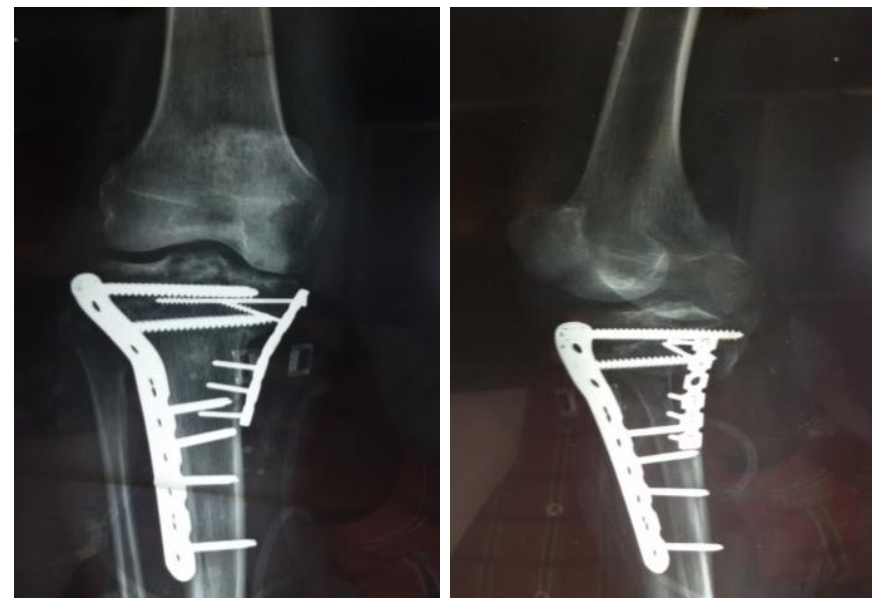

Immediate post op
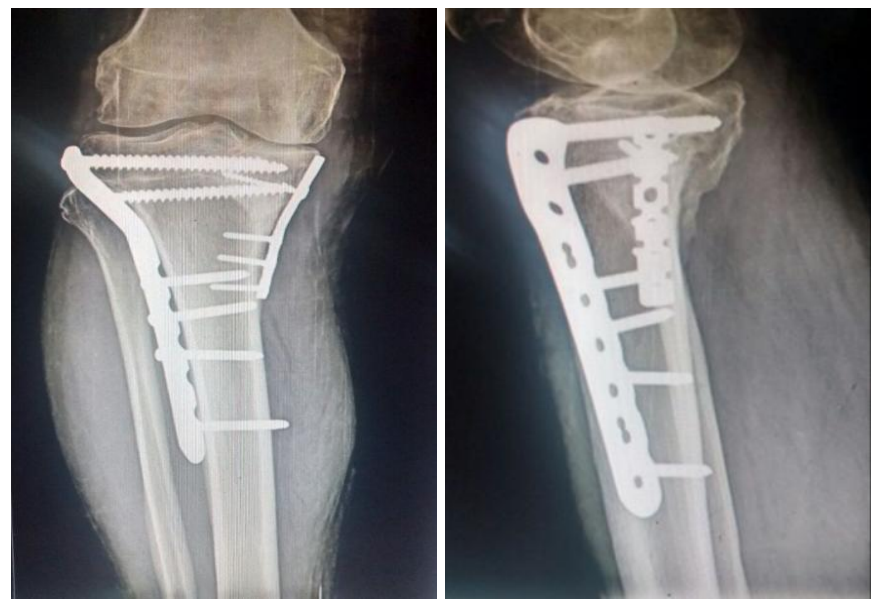

18 Months Post Op

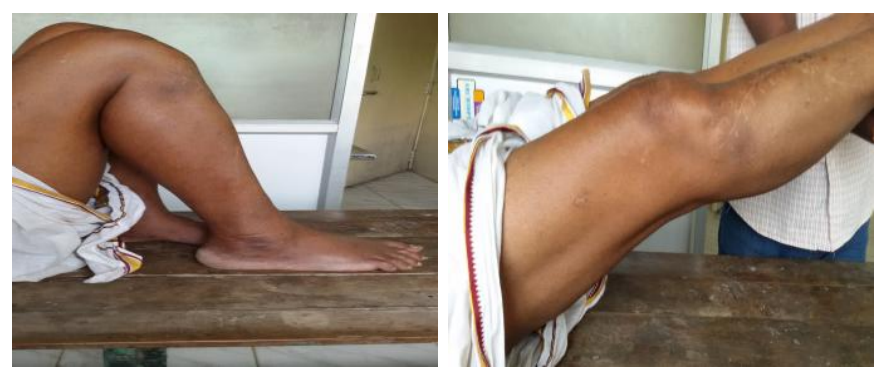

Range of movements

\section{Reference}

1. Schatzker J, Fractures of the Tibial Plateau, in The Rationale Of Operative Fracture Care, 2005, 447-469.

2. JL Marsh MD. Tibial Plateau Fractures, in Rockwood and Green's Fracture in Adults, Wolters Kluwer, 2015, 2303-2367.

3. Mathew I. Rudloff, Fractures of the Lower Extremity, in Campbell's Operative Orthopaedics, Elsevier, 2013, 2668-2724.

4. Marsh JL. Tibial Plateau Fractures, in Rockwood and Green's Fracture In Adult, Wolters Kluwer \& Lippincott Williams and Wilkins, 2010, 1782-1830.

5. EG Hassankhani. Treatment of Complex Proximal Tibial fractures (Type $5 \& 6$ Scatzker Classification) by Double Plate fixation with Single Anterior Incision, Open Journal of Orthopaedics. 2013; 3:208-212.

6. G Prasad. Functional Outcome of Schatzker Type 5 and 6 Tibial Plateau fractures treated with dual plates, Indian Journal of Orthopaedics. 2013, 47(2).
7. Pelsar PM. Controversies in the management of tibial plateau fractures, SA Orthopaedic Journal. 2010, 75.

8. Pun TB. Outcome of Schtazkers type 5 and type 6 fractures, Indian Journal of Orthopaedics. 2014, 48(1).

9. Zhang Y, Treatment of Complicated Tibial Plateau fractures with Dual Plating via 2 incision technique, Orthosupersite. Com, 2012, 35(3).

10. Oh CW. Double plating of unstable proximal tibial fractures using minimally invasive percutaneous osteosynthesis technique, Acta Orthopaedia, 2006; 77(3):524-530.

11. Ee al. Unstable Bicondylar Tibial Plateau Fractures: A Clinical Investigation, J Orthop Trauma. 2008; 22:673679.

12. NS, MW, Barie DP. Complications associated with internal fixation of High energy bicondylar tibial plateau fractures utilising a two incision technique, J Orthop Trauma. 2004, 18.

13. V. New Trends and technique in open reduction and internal fixation of fractures of tibial plateau, $\mathrm{J}$ Bone Joint Surg [Br]. 2009, 91-B.

14. B. Functional outcomes of severe bicondylar tibial plateau fractures treated with dual incision and medial and lateral plates, J Bone and Joint Surgery [Am], 88-A, 2006.

15. PV Freeman MA, The movement of normal Tibiofemoral joint, J Biomech. 2005, 38.

16. ML, HM Bhattacharyya T. The posterior shearing tibial plateau fracture: treatment and results via a posterior approach, J Orthop Trauma. 2005, 19.

17. PA, TG Papagelopoulous PJ. Complication after tibial plateau fracture surgery, Injury, 2006, 37.

18. HG Jacofsky DJ. Tibial Plateau Fractures, In:Scott WN. Insall \& Scott Surgery of Knee. Churchill Livingston. Elsevier, 2006.

19. EM. "Reliability of Locked PLating in Tibial Plateau fractures with medial component," Orthop Traumatol Surg Res, 2012, 98.

20. RJ, BJJ Ricci WM, Treatment of complex proximal tibia fractures with less invasive skeletal stablization system, J Orthop Trauma. 2004, 18.

21. MTNJMJ Phisitkul P, Complications of locking plate fixation in complex proximal tibial injuries, J Orthop Trauma. 2007; 21:83-91.

22. COT. Society, Open Reduction and Internal fixation compared with circular fixator application for bicondylar tibial plateau fractures. Results of a multicenter, prospective randomised clinical trial, J Bone and Joint Surg [Am]. 2006; 88:2613-2623.

23. MMRM Gosling $\mathrm{T}$, The Less Invasive Stablization system for Bicondylar fractures of the proximal tbia, Orthopaedic Trauma Association 18 Annual Meeting, Toronto, Canada, 2002.

24. J Watson. Tibia-Proximal, in AO Principles of Fracture Management, 2000, 499-519.

25. M Williams, J Mills MD, Sean Norle E. ORIF of high energy tibial plateau fractures, OCNA, 2002; 33:177.

26. HD Koval KJ. Tibial plateau fractures-Evaluation and treatment, J. Am. Acad. Orthop. Surg. 1995; 3(2):86-94.

27. MRBD Schatzker J. The tibial plateau fracture. The Toronto Experience 1968-1975, Clin Orthop, 1979; 138:94-104.

28. HSE. Indication for surgical treatment of tibial plateau fractures, Clin Orthop, 19941; 302:199-205.

29. LJ Hohl M, Fractures of tibial condyle: A clinical and 
experimental study, J Bone and Joint Surg. 1956 38A:1001-1018.

30. MCBFO David, M Hahn. Current Principles of treatment in clinical practice of Articular fracture, CORR, 2004 423:27-32.

31. HM Gauze Witz. Significance of Early motion in the treatment of tibial plateau fractures, Clin Orthop, 1986; 202:135.

32. SENSSK, KK Egol KA. Treatment of complex tibial plateau fractures using the less invasive stablisation system plate: Clinical experience and a laboratory comparison with double plating, The Journal of Trauma. 2004; 69(2):340-346.

33. KJBK Higgins TF. Biomechanical Analysis of Bicondylar tibial plateau fixation: how does lateral locking plate fixation compare to dual plate fixation, $\mathbf{J}$ ortho Trauma. 2007; 21(5):301-6.

34. JRM Ratcliff, FWM Werner, JK Green, HBJ MD. Medial buttress versus Lateral locked plating in a cadaver medial tibial plateau fracture model, J Orthop Trauma. 2007; 21(7):444-448.

35. KDKJ Higgins TF, Incidence and morphology of the posteromedial fragment in bicondylar tibial plateau fractures, J Orthop Trauma. 2009; 23(1):45-51.

36. AMSM Ali. The strength of different fixation techniques for bicondylar tibial plateau fractures-a biomechanical study, Clinical Biomechanics, 2003, 846-870.

37. BPMB Liow RY, Spiral Computed tomography with two and three dimensional reconstruction in the management of tibial plateau fractures, Orthopaedics, 1999; 22:929932.

38. BPBC Wicky S. Comparison between Standard radiography and Spiral CT with $3 \mathrm{D}$ reconstruction in the evaluation, classification and management of tibial plateau fractures, Eur Radiol, 2000; 10:1227-1232.

39. D Levay, History of Orthopaedics, 1990, 625-592.

40. SR Jones. Orthopaedic Surgery of Injuries, 1921, 1(86).

41. AAG. Fracture of Lateral Tibial Condyl treated by skeletal traction and early mobilization. A review of sixty cases with special reference to long term results, J Bone and Joint Surg. 1956; 38-B:699.

42. J Moore TM, Harvey JP. Roentgenographic measurement of tibial plateau depression due to fractures, $\mathrm{J}$ Bone and Joint Surg. 1974; 56A:155.

43. HM Bowes DN. Tibial condyl fractures: evaluation of treatment outcome, Clin Orthopaedic, 1982; 171:104.

44. RCR Blokker CP. Tibial plateau fracctures: an analysis the result of treatment in 60 patients, Clin Orthop, 1984; 182:193.

45. RCDBN Jensen DB, A Comparison of conservative and surgical treatment, J Bone and Joint Surg. 1990; 72:4952.

46. JM Honkonen SE. Classification of fractures of tibial condyles, J Bone and Joint Surg. 1992; 74B:840.

47. LP Tsherne H, Tibial Plateau Fractures. Management and Expected results, Clin Orthop Relat Res, 1993; 292:87100.

48. SSDT Marsh JL, External fixation and limited internal fixation for complex fractures of the tibial plateau, J Bone and Joint Surgery. 1995; 77A:661.

49. MJ Weigel DP, High energy fractureof tibial plateau: knee function after longer follow-up, J Bone and Joint Surg. 2002; 84A:1541-1551.

50. W. Posteromedial Supine approach for reduction and fixation of medial and bicondylar tibial plateau fractures, 